UDC: 655.552:001.891.5:330.47:33.053.22(072)

DOI: 10.26697/ijes.2019.4.50

\section{Review of the methodological manual "Methodology for Determining Whether a Blockchain Token Corresponds to a Digital Asset", author Aleksandr Kud}

\author{
Professor Marchenko O. S. (Reviewer) ${ }^{1}$ \\ ${ }^{l}$ Yaroslav Mudryi National Law University, Ukraine
}

\section{Review:}

Methodological manual of A. Kud is dedicated to determining the main characteristics of a blockchain token as an element of institutional cryptoeconomy.

A. Kud has presented a scalable, easily implementable and properly formalized methodology for determining the content of the term "digital asset" among a set of definitions for the terms "blockchain token", "digital currency", "virtual currency", "cryptocurrency", "digital asset", "virtual asset", "crypto asset", "digital money", "virtual money" and "electronic money".

The author pays extra attention to the substantiation of the economic component in the context of the definition of the term "digital asset", which is represented by the component "in the form of a unique identifier".

Due to the features of unique identifiers described by the author, natural persons and economic entities get the ability to keep balance accounting of a digital asset and calculate economic activity indicators.

The manual defines a blockchain token as an accounting unit of information in the distributed ledger technology (DLT), which is the basis for the methodology for determining the correspondence of a blockchain token to a digital asset.

The objective of the manual is to unify the approach to the main components of the term "digital asset" and correspondence of accuracy of comparing each separate blockchain token with the criteria of a digital asset in institutional economy.

A. Kud proposes a fairly simple methodology for determining the value of any randomly selected token.

The manual is written in an accessible and easy to understand manner.

The methodological manual includes an extensive thesaurus, which allows avoiding ambiguous understanding of widely used terms.

This manual can be recommended to both specialists, who are involved in legal regulation in the field of institutional cryptoeconomy, as well as to a wide range of investors, who are interested in systematizing their views on cryptoinstruments as a whole.

\section{References:}

Kud, A. A. (2019). Methodology for Determining Whether a Blockchain Token Corresponds to a Digital Asset: methodical manual. Kharkiv: KRPOCH. doi:10.26697/9786177089079.2019
Information about the reviewer:

Marchenko Olha Serhiivna - Doctor of Economic Sciences, Professor, Professor of the Department of Economic Theory, Yaroslav Mudryi National Law University, Kharkiv, Ukraine.

Research interests: methodology and theory of economics, business consulting, management of consulting activity, economics and organization of legal consulting; http://orcid.org/0000-0003-47619620.

\section{Email Reviewer:}

Ol.mar4encko2011@ukr.net 